\title{
COMPARATIVE HISTOLOGICAL STUDY OF TWO DIFFERENT PULP CAPPING AGENTS IN RABBITS TEETH
}

\author{
Rehab Khalil Safy* and Mai Hamdy Ragab**
}

\begin{abstract}
Objective: Evaluation of the histological pulp response following direct pulp capping with Galla Chinensis Extract (GCE) in comparison to Mineral Trioxide Aggregate (MTA) in rabbits' teeth.

Methodology: Intentional pulp exposure on the labial surfaces of permanent central incisors of twenty male rabbits was done. Split mouth technique was utilized for applying the capping material where MTA was used for capping upper and lower right central incisors while, GCE was used for capping upper and lower left central incisors. The teeth were restored by glass inonomer cement (GIC) as permanent restorations. Rabbits were divided randomly into two groups 10 rabbits each according to pulp capping period (two and four weeks). After animal scarification teeth were dissected and prepared for histological evaluation using Hematoxylin Eosin (HE) stains.
\end{abstract}

Results: GCE group showed significantly higher mean dentin bridge thickness than MTA group at four weeks, also it showed significantly higher median inflammatory cell scores than MTA group at both time intervals.

Conclusions: GCE is a promising direct pulp capping material with less biological pulp response in comparison to MTA.

Key words: Pulp capping, GCE, MTA, Histological evaluation.

\section{INTRODUCTION}

Treatment of exposed vital pulp through direct pulp capping demanding covering of the exposed area by a capping material to encourage development of protective barrier and to maintain pulp vitality ${ }^{[1,2]}$. Introduction of new pulp capping materials that have remineralizing potency and attach to dentin through mineral rich interface is one of significant objectives in dental field ${ }^{[3]}$. Ideal pulp capping material ought to give reasonable microenvironment to dentin bio mineralization as well as having antibacterial effects, resist further pulp injury resulting from the residual bacteria in

* Operative Dentistry Department, Faculty of Dentistry, Suez Canal University, Egypt

** Endodontic Department, Faculty of Dentistry, Suez Canal University, Egypt 
dental pulp tissue. Therefore, a stable and healthy environment for pulp healing is essential for pulp repair. Lately, Mineral Trioxide Aggregate (MTA) has considered as substitute for Calcium Hydroxide ${ }^{[4]}$. In vivo direct pulp-capping studies investigating MTA in comparison to calcium hydroxide revealed better pulp healing with MTA than with calcium hydroxide. These studies have demonstrated more dentin bridgeformation and less inflammatory reaction in pulp tissues capped with MTA in comparison to the calcium hydroxide group ${ }^{[5,6]}$.

In spite of the considerable number of advantages of MTA as biocompatibility and sealing ability, the material has several limitations such as high solubility, long setting time, staining potential and costly ${ }^{[7]}$. Moreover, several studies have demonstrated that MTA has restricted and questionable antibacterial properties ${ }^{[8,9]}$. Hence it seemed to be sensible to blend antibacterial agents with MTA in some examinations to improve its antibacterial capability. Several investigations have endeavored to enhance its antibacterial properties by blending it various concentration of $\mathrm{NaOCl}$, $\mathrm{K}-\mathrm{Y}$ jelly and various concentration of $\mathrm{CaCl} 2{ }^{[10,11]}$. Trials involving mixing of $0.12 \%$ Chlorohexidine (CHX) with MTA brought a significantly higher antibacterial activity contrasted with to MTA mixed with distilled water ${ }^{[12]}$, anyway the outcomes likewise demonstrated that mixing CHX with MTA had a significant negative impact on the formation of reparative dentin following pulp capping ${ }^{[13]}$.

So looking for novel alternative bioactive capping materials with antibacterial activity and of lower cost could be a promising alternative for this clinical quandary. Galla Chinensis Extract (GCE), a natural traditional Chinese medicine mainly consisting of tannic and Gallic acids, is one of the typical alternatives to fluoride in dentistry. Multiple studies have recorded the ability of GCE extract to inhibit the cariogenic bacteria and enamel demineralization/ remineralization balance is modulated positively ${ }^{[14}$, ${ }^{15]}$. Therefore, the objective of the current study was to investigate the histological response of a healthy rabbit pulp tissue to direct pulp capping with GCE material in comparison to MTA.

\section{MATERIAL AND METHODS}

All animals included in the current study were fit in with the rules for animal experiments of research ethical committee, Faculty of Dentistry Suez Canal University. Materials used are listed in Table 1.

TABLE (1): Materials` composition, manufacturer and lot numbers:

\begin{tabular}{|l|l|l|l|}
\hline Materials & Composition & Manufacturer & Lot number \\
\hline $\begin{array}{l}\text { Mineral Trioxide Aggregate } \\
\text { (MTA) }\end{array}$ & $\begin{array}{l}\text { Powder: 75\% type I Portland cement, } \\
20 \% \text { bismuth oxide, 5\% calcium } \\
\text { sulfate dehydrate. Liquid: Tricalcium } \\
\text { aluminate and water. }\end{array}$ & (Angelus, Londrina, PR, Brazil) & $\begin{array}{l}\text { Powder: } \\
12002493 \\
\text { Liquid:120407 }\end{array}$ \\
\hline Galla Chinensis Extract (GCE) & $\begin{array}{l}\text { Powder: GCE 82\% (rhus chinensis mill). } \\
\text { Liquid: Distilled water }\end{array}$ & $\begin{array}{l}\text { Bulk supplements } \\
\text { 7511Eastgate Road } \\
\text { Henderson,NV89011 }\end{array}$ & $121 \mathrm{D} 0906$ \\
\hline Glass Ionomer Cement (GIC) & $\begin{array}{l}\text { Fluoro-aluminosilicate glass, poly acrylic } \\
\text { and tartaric acid }\end{array}$ & $\begin{array}{l}\text { (self-cured Riva, SDI,Australia) } \\
\text { B1004281 }\end{array}$ & \\
\hline
\end{tabular}




\section{1- Selection of the experimental animals}

Twenty New Zealand rabbits were used in the current study; their age was around 12 months and weighting three $\mathrm{kg}$. They were controlled diet and received daily care in the animal house of Faculty of Veterinary Medicine, Suez Canal University.

\section{2- Pre-operative considerations and Anesthesia}

Each rabbit was anaesthetized through administration of $20 \mathrm{mg} / \mathrm{Kg}$ Sodium Thiopental solution intra muscular in the quadriceps femorais muscle using needle with an appropriate gauge. The injection was conveyed gradually and consistently followed by massaging of the injection site to ensure optimal distribution of the drug. The oral cavity was disinfected with $0.12 \%$ chlorohexidine disinfectant (Ultra dent, USA). An intra-oral dry field was achieved through using of cotton rolls and gauze swabs.

\section{3- Animals grouping and pulp capping procedures:}

Eighty central incisors from the twenty rabbits were utilized in the current study distributed as two upper and two lower central incisors in each rabbit. Split mouth technique was utilized where the two tested materials were used in both sides of the mouth in the same animal.

Class V cavity preparation was done in the gingival third of the labial surface of each tooth in a standardized protocol. The cavity preparation was done by using sterile carbide inverted cone bur (\#35, Hager\& Meisinger GmbH, Germany) mounted on high-speed contra-angle (TC Motor 3000, France) under copious sterile water spray. An intentional pin point pulp exposure was then made by a sterile small (\#016) round diamond bur (Hager\& Meisinger GmbH, Germany) in the middle of the pulpal floor. Proper hemostasis was achieved through controlling of bleeding by pellets of cotton moistured with sterile saline with gentle pressure. For avoidance of cross contamination each cavity was prepared by a sterile bur. Manipulation of MTA was done according the manufacturer' instructions and used for capping upper and lower right incisors with minimal pressure (G1). Meanwhile, freshly mixed GCE was used for capping of upper and lower left incisors in each rabbit respectively (G2). The GCE was blended with sterile distilled water to a slurry mix then; it was used to cap the exposure area through utilizing Liner Placement Instrument (Caulk, Dentsply). Immediately after capping procedure each cavity was restored with self-cured glass ionomer filling as a permanent restoration.

\section{4- Post operative procedures:}

All rabbits were cared for as indicated by convention of Canadian Committee of Animal Care [16]. They were maintained in separate cages and were fed with a special soft diet. Each group was randomly subdivided into two subgroups (10 rabbits each), according to the pulp capping period (two and four weeks). Where teeth capped with MTA for two weeks in the subgroup (G 1.1) and capped with MTA for four weeks in the subgroup (G 1.2). Meanwhile in (G 2.1) they were capped with GCE for two weeks and capped with GCE for four weeks in the subgroup (G 2.2).

After rabbit scarification teeth were fixed in $10 \%$ neutral buffered formalin solution and demineralized through immersion in EDTA for 30 days. Teeth were fixed in paraffin blocks then cut longitudinally through the pulp in a labialpalatal plane ${ }^{[17]}$. Slides were prepared and staining procedure was performed by in $\mathrm{H} \& \mathrm{E}$ stain (Carl Zeiss Imager D1 Axio, Goettingen, Germany), following a standardized protocol ${ }^{[18]}$. The slides were photographed and examined by optical microscopy utilizing the Image J program (version 1.47, National Institutes of Health, Bethesda, MD, USA) and Olympus microscope (Olympus EVOLT E-330). The results were evaluated by one evaluator using a light microscope at different magnifications where each histological slide has been assessed by scores from 1 to 4 ; 1 was the highest and 4 was the lowest outcome ${ }^{[19]}$. 


\section{I- Thickness of dentin bridge formation}

1. Above $250 \mu \mathrm{m}$.

2. from 150 to $249 \mu \mathrm{m}$.

3. from 1 to $149 \mu \mathrm{m}$.

4. Incomplete or no dentin bridge formation.

\section{II- Intensity of pulp inflammation}

1. No or limited number of inflammatory cells.

2. Mild: less than 10 inflammatory cells.

3. Moderate: 10- 25 inflammatory cells.

4. Severe: higher than 25 inflammatory cells.

For the statistical analysis of parametric data, Student's t-test was used to compare between the two groups. For non-parametric data; Mann-Whitney U test was used to compare between the two groups as well as the two follow up periods. The significance level was set at $\mathrm{P} \leq 0.05$. Statistical analysis was performed with IBM SPSS Statistics for Windows, Version 22.0. Armonk, NY: IBM Corp.

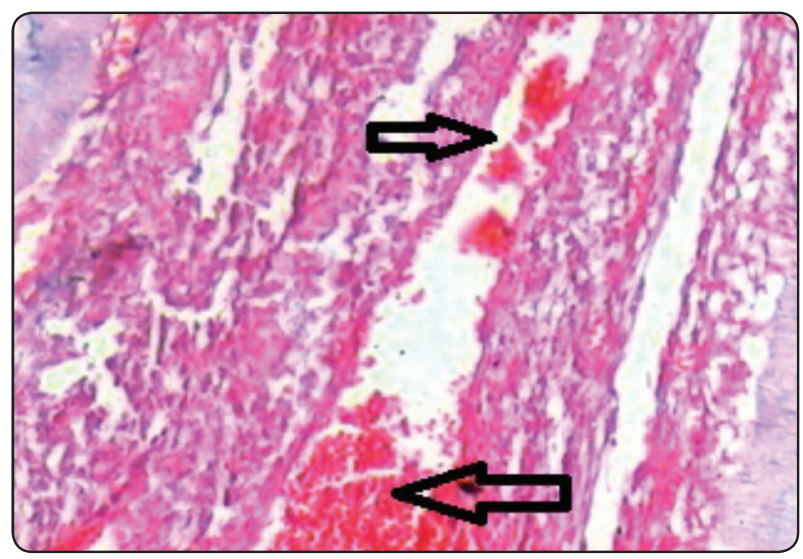

Fig. (1): Pulp cap with GCE for two weeks showing inflamed pulp tissue and dilated blood vessels (H \& E X 200).

\section{RESULTS}

\section{Dentin bridge thickness}

For the two weeks pulp capping period both of GCE and MTA in all specimens showed no dentin bridge formation representing score 4 (Figs. 1, 2). Meanwhile in the four weeks pulp capping period, GCE specimens (G2.2) showed dentin bridge formation where, $85 \%$ of the specimens representing score 2 (from 150 to $249 \mu \mathrm{m}$ ) and $15 \%$ representing score 3 (from 1 to $149 \mu \mathrm{m}$ ) (Fig. 3). Also all MTA specimens capped for four week (G1.2) showed dentin bridge formation where, 90\% of specimens showed score 3 (from 1 to $149 \mu \mathrm{m}$ ) while the other $10 \%$ of specimens showed score 2 (from 150 to $249 \mu \mathrm{m}$ ) (Fig. 4). A single specimen of pulp capped with GCE for four weeks showed secondary dentine (osteodentine) formation within the pulp tissue (Fig. 5). The specimens in which pulp was capped with GCE for four weeks (G2.2), showed significantly higher mean dentin bridge thickness than those capped with MTA for the same capping period (G1.2) (Fig.7) \& table (2).

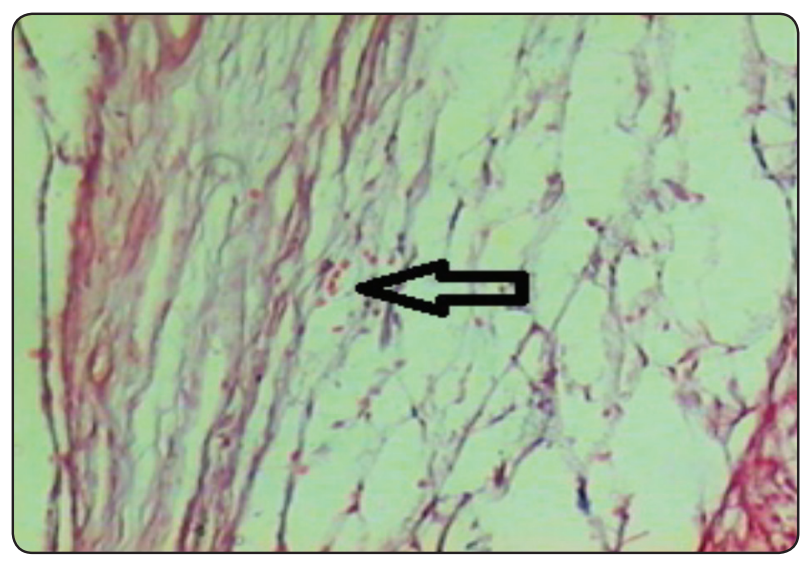

Fig. (2): Pulp cap with MTA for two weeks showing less pulp inflammation than that detected with GCE (H \& E X 400). 


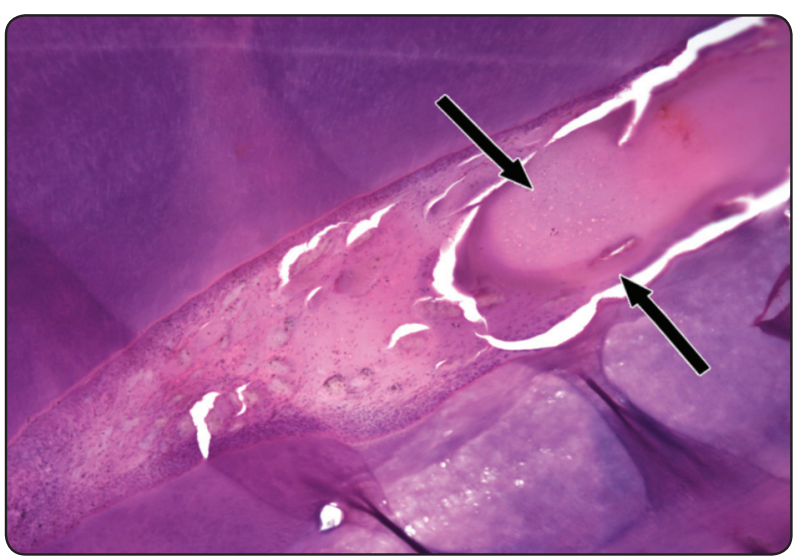

Fig. (3): Pulp cap with GCE for four weeks showing thick dentin bridge formation $(50 \mathrm{X})$.

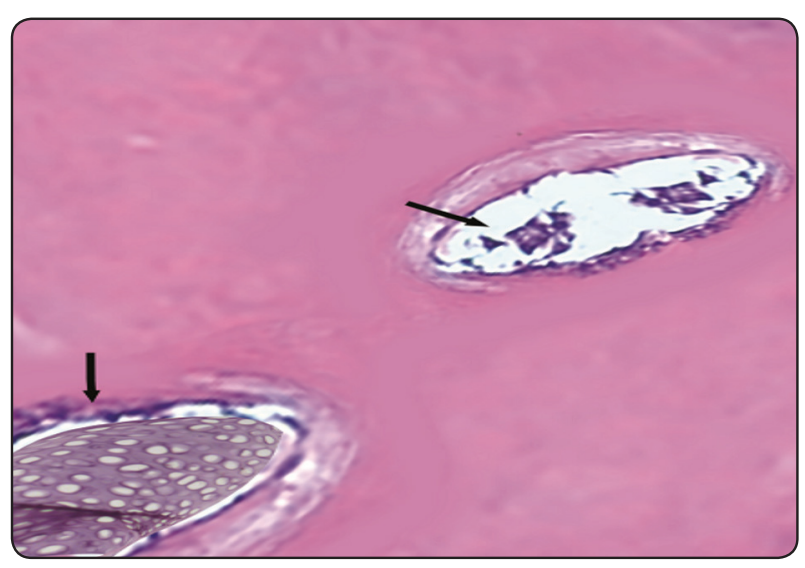

Fig. (5): Pulp cap with GCE for four weeks showing secondary dentine (osteodentine) formation (H \& E X 400).

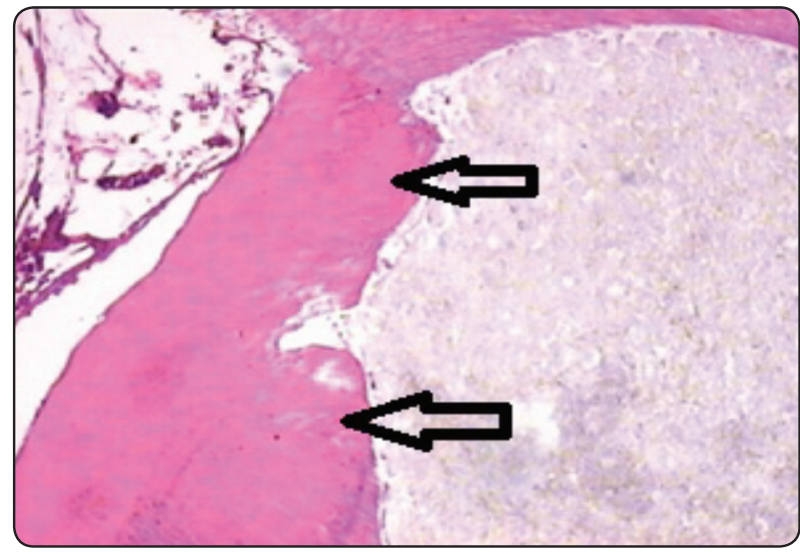

Fig. (4): Pulp cap with MTA for four weeks showing dentine bridge formation $(50 \mathrm{X})$.

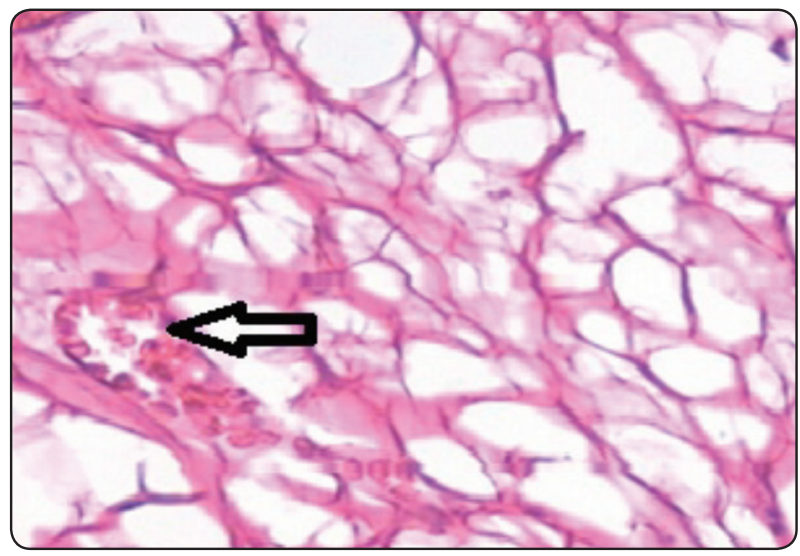

Fig. (6): Pulp cap with GCE for four weeks showing mild inflammation and edema of the pulp tissues (H \& E X 400).

TABLE (2): Mean, standard deviation (SD) values and results of Student's t-test for the comparison between dentin bridge thicknesses in the two groups at four weeks.

\begin{tabular}{|c|c|c|c|c|c|c|c|}
\hline \multicolumn{3}{|c|}{ GCE } & \multicolumn{3}{c|}{ MTA } & \multirow{2}{*}{ P-value } & Effect size (d) \\
\hline Mean & SD & $95 \%$ CI & Mean & SD & $95 \%$ CI & \\
\hline 166.8 & 20.6 & $155.9-177.8$ & 99.9 & 11.6 & $93.7-106.1$ & $<0.001 *$ & 4.002 \\
\hline
\end{tabular}

*: Significant at $P \leq 0.05$ 


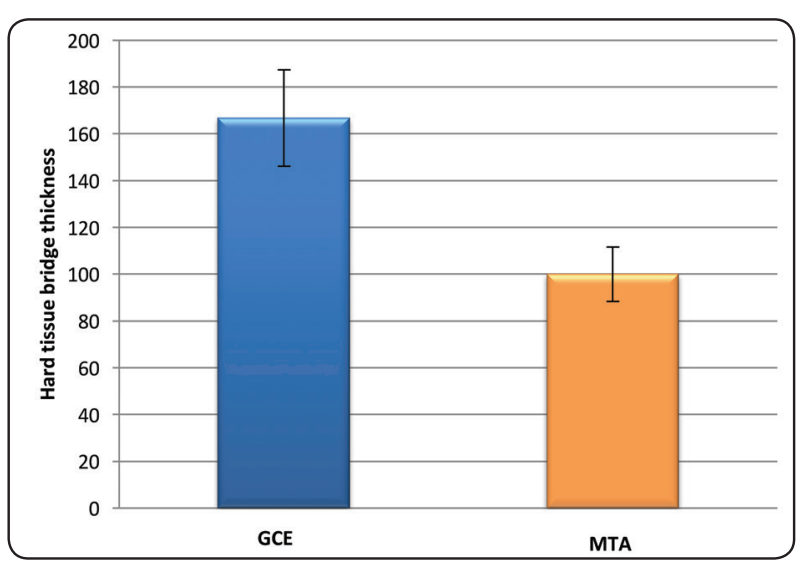

Fig. (7): Bar chart representing mean values of dentin bridge thickness in the GCE and MTA groups

\section{2- Intensity of pulp inflammation}

Data in table (3) and Fig. (8) revealed that after pulp capping for two weeks, GCE sub group (G2.1) showed significantly higher median inflammatory cell scores than MTA subgroup (G1.1). Where $75 \%$ of specimens of GCE group showed score 3 (moderate: average number of $10-25$ cells.) while only $15 \%$ of specimens showed score 2 (mild: average number less than 10 cells). As regard to MTA (G1.1) $100 \%$ of specimens showed score 2 (mild: average number less than 10 cells). After four weeks of pulp capping, the results showed that both of MTA (G1.2) and GCE (G2.2) subgroups showed a statistically significant decrease in mean inflammatory cell counts. Also the subgroup (G2.2) showed significantly higher median inflammatory cell scores than subgroup (G1.2). Where 90\% of specimens in the subgroup (G2.2) showed score 2 (mild: average number less than 10 cells) while the other $10 \%$ of specimens showed score 1 (absent or very few cells) (Fig. 6). Meanwhile, all specimens in the subgroup (G1.2) showed absence of inflammatory cells from the pup tissue.

TABLE (3): Median, range values and results of Mann-Whitney $U$ test for the comparison between inflammatory cell scores in the two groups at the two follow up periods.

\begin{tabular}{|c|c|c|c|c|c|c|}
\hline \multirow{2}{*}{ Material } & \multicolumn{2}{|c|}{ GCE } & \multicolumn{2}{|c|}{ MTA } & \multirow{2}{*}{ P-value } & \multirow{2}{*}{ Effect size $(\mathrm{d})$} \\
\cline { 1 - 4 } Time & Median & Range & Median & Range & & 2.455 \\
\hline 2 weeks & 10.2 & $7-12.33$ & 3.5 & $2-7$ & $0.014^{*}$ & 2.001 \\
\hline 1 month & 2.5 & $0-4.67$ & 0 & $0-0$ & $0.001 *$ & 2.01 \\
\hline
\end{tabular}

*: Significant at $P \leq 0.05$

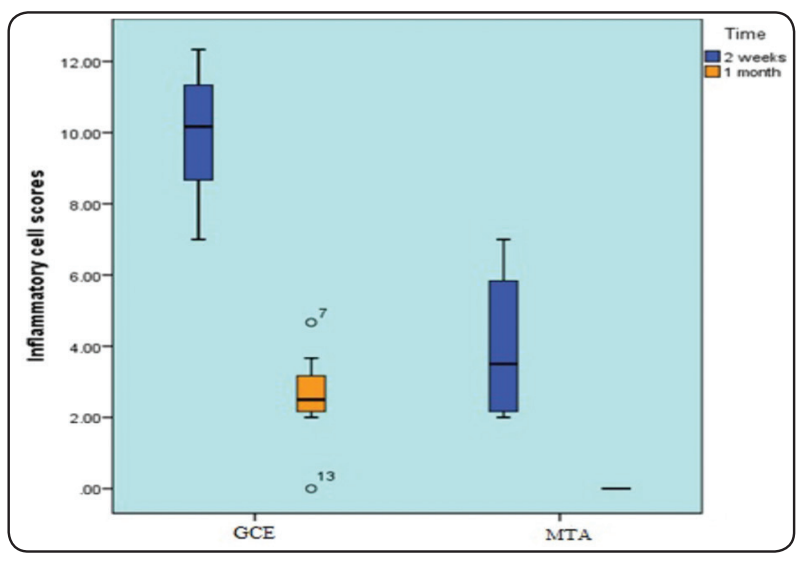

Fig. (8): Box plot representing median and range values for inflammatory cell counts in the two groups (Circles represent outliers)

\section{DISCUSSION}

Direct pulp capping is a procedure of capping the traumatically exposed vital pulp with a material to preserve its vitality and maintain its biological and functional properties. For a long period, Calcium hydroxide was the material of choice for pulp capping due to its capacity to encourage the formationof reparative dentin and its high antibacterial efficiency ${ }^{[20]}$. However, it exhibits several drawbacks, like inadequate sealing, presence tunnel defects in the reparative dentin, and high solubility ${ }^{[21-23]}$. Searching for alternative pulp capping materials leads to introduction of calcium 
silicate-based materials, like mineral trioxide aggregate (MTA). Multiple studies proved that MTA is superior to calcium hydroxide but exhibits some drawbacks such as poor handling properties, high cost, and slow setting time ${ }^{[24-26]}$. So that, to overcome the limitations of the commercially available calcium silicate based materials new bio-inspired pulp capping materials with better clinical properties should be introduced. Recently, several studies were carried out to investigate the mechanism of efficacy of natural herbal medicines such as GCE as anti-cariogenic materials ${ }^{[27]}$. GCE is a promising new remineralizing therapeutic strategy; it proved its ability of modulating the mineral balance of the hard tooth structure at initial stages of caries ${ }^{[28]}$. Moreover, it might be promptly incorporated into endodontic irrigants and dentin adhesives due to its biocompatibility as well as biochemical and biomechanical properties ${ }^{[29]}$. So that it was recommended in the current study to investigate the capability of GCE as a pulp capping material in comparison to the MTA. The selected animal model in the current study was rabbits in light of the fact that their pulp tissues are comparable with that of human ${ }^{[30]}$. The pulp capping period were prescribed by several previous studies to be short term extending only for four weeks ${ }^{[31,32]}$. They legitimized that rabbit teeth erupt continuously; this eruption is held in balance by dental abrasion from their eating regimen which is rich in fiber ${ }^{[33]}$.

Numerous previous studies revealed that during pulp capping, hydroxide ions of MTA stimulate the release of alkaline phosphatase and BMP-2, which play a role in reparative hard tissues formation [34, 35]. The outcomes of the current study revealed that the GCE subgroup showed thicker dentin bridge formation than the MTA subgroup in the four weeks pulp capping period. This outcome could be credited to the chemical make-up of the GCE which have been theorized to be calcium ion carriers, providing the demineralized hard tissue structure with calcium ions from the remineralization solution. Gallic acid is considered as the main effective component of GCE that enhance the calcium ion deposition on the demineralized tissue ${ }^{[36]}$. Additionally, an investigation examining the shape and structure of hydroxyapatite crystals with Gallic acid treatment recommended that Gallic acid may influence the process of the hydroxyapatite formation [37]. Appearance of osteodentine formation within the pulp tissue in a specimen capped with GCE for four weeks may predict that GCE could result in intra pulpal calcification so that, we recommend further studies to reveal whether GCE could result in complete pulp calcification or not.

Concerning the inflammatory scores of both capping materials, the results showed significantly less pulp inflammation with the MTA in both capping periods of the study in contrast with the GCE group. This could be attributed to the high alkalinity of MTA (10.2) that increases after 3 hours of setting to $12.5^{[38]}$, in contrast with the low $\mathrm{pH}$

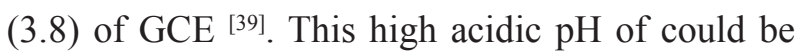
responsible for more pronounced inflammatory response in the GCE group at the two weeks pulp capping period. By time, the inflammatory score dramatically decreased in the GCE group from the two weeks to the four weeks capping period. This could be attributed to neutralization of the high acidity of GCE with the pulp tissue fluid over time. So, further studies with longer pulp capping periods are recommended to reveal whether the inflammatory cells will disappear completely or not from the pulp tissue capped with GCE by longer time interval. Also immune histochemical studies could be of value to investigate the biological effect of the GCE on the pulp stem cells.

\section{CONCLUSIONS}

Within the limitations of the current study it could be concluded that GCE is a promising direct pulp capping material with less biological pulp response indicating less quality of healing in comparison to MTA. 


\section{REFERENCES}

1. Pashley DH. Dynamics of the pulpo-dentin complex. Crit Rev Oral Biol Med 1996; 7: 104-133.

2. Bergenholtz G. Advances since the paper by Zander and Glass (1949) on the pursuit of healing methods for pulpal exposures: historical perspectives. Oral Surg Oral Med Oral Pathol Oral Radiol Endod 2005; 100: S102-S108.

3. Gandoli MG, Taddei P, Siboni F, Modena E, De SteFano ED, Prati C. Biomimetic remineralization of human dentin using promising innovative calcium-silicate hybrid "smart" materials. Dent Mater 2011;27:1055-69.

4. Swarup S, Rao A, Boaz K, Srikant N, Shenoy R. Pulpal response to nano hydroxyapatite, mineral trioxide aggregate and calcium hydroxide when used as a direct pulp capping agent: an in vivo study. J Clin Pediatr Dent. 2014;38(3):201-6.

5. Asgary S, Eghbal MJ, Parirokh M, Ghanavati F, Rahimi H. A comparative study of histologic response to different pulp capping materials and a novel endodontic cement. Oral Surg Oral Med Oral Pathol Oral Radiol Endod 2008; 106: 609- 614

6. de Souza Costa CA, Duarte PT, de Souza PP, Giro EM, Hebling J. Cytotoxic effects and pulpal response caused by a mineral trioxide aggregate formulation and calcium hydroxide. Am J Dent 2008; 21: 255-261.

7. Torabinejad M, Parirokh M. Mineral trioxide aggregate: a comprehensive literature review--part II: leakage and biocompatibility investigations. JOE 2010;36(2):190-202.

8. Torabinejad M, Hong CU, Pitt Ford TR, Kettering JD. Antibacterial effects of some root end filling materials. JOE. 1995;21(8):403-6.

9. Yasuda Y, Kamaguchi A, Saito T. In vitro evaluation of the antimicrobial activity of a new resin-based endodontic sealer against endodontic pathogens. J Oral Sci. 2008;50(3):309-13.

10. Kogan P, He J, Glickman GN, Watanabe I. The effects of various additives on setting properties of MTA. JOE 2006;32(6):569-72.

11. Yan P, Peng B, Fan B, Fan M, Bian Z. The effects of sodium hypochlorite $(5.25 \%)$, Chlorhexidine (2\%), and Glyde File Prep on the bond strength of MTA-dentin. JOE. 2006;32(1):58-60.

12. Stowe TJ, Sedgley CM, Stowe B, Fenno JC. The effects of chlorhexidine gluconate $(0.12 \%)$ on the antimicrobial properties of tooth-colored ProRoot mineral trioxide aggregate. JOE. 2004;30(6):429-31.
13. Hamed Manochehrifar a, Masoud Parirokh b, Sina Kakooei $b^{*}$, Mohammad Mehdi Oloomi c. The Effect of Mineral Trioxide Aggregate Mixed with Chlorhexidine as Direct Pulp Capping Agent in Dogs Teeth: A Histologic Study. IEJ 2016;11(4): 320-324.

14. Huang SB, Gao SS, Cheng L, Yu HY. Combined effects of nano-hydroxyapatite and GCE chinensis on remineralization of initial enamel lesion in vitro. J Dent 2010; 38:811-9.

15. Cheng L, ten Cate JM. Effect of GCE chinensis on the in vitro remineralization of advanced enamel lesions. Int $\mathrm{J}$ Oral Sci 2010;2:15-20.

16. Fenwick N, Danielson P, Griffin G. Survey of Canadian animal-based researchers' views on the Three Rs: replacement, reduction and refinement. PLoS One 2011; 6(8).

17. Decup F, Six N, Palmier B, Buch D, Lasfargues JJ, Salih E. Bone sialoprotein-induced reparative dentinogenesis in the pulp of rat's molar. Clin Oral Invest 2000;4:110-9.

18. Kiernan J.A. Histological and histochemical methods: theory and practice (fourth ed.), Scion, Bloxham, UK (2008)

19. Faraco-Junior IM, Holland R. Histomorphological response of dogs' dental pulp capped with white mineral trioxide aggregate. Braz Dent J 2004; 15:104-108.

20. Mohammadi Z and Dummer P. M. H. Properties and applications of calcium hydroxide in endodontics and dental traumatology. International Endodontic J 2011;44, 8: 697-730.

21. Ferracane J. L, Materials in Dentistry: Principles and Applications, Lippincott Williams \& Wilkins, Philadelphia, $\mathrm{Pa}$, USA, 2nd edition, 2001.

22. Cox C. F, Subay Ostro R. K., E., Suzuki S, Suzuki S. H, “Tunnel defects in dentin bridges: their formation following direct pulp capping," Operative Dentistry 1996;21: 4- 11.

23. Schuurs A. H. B., Gruythuysen R. J. M, Wesselink P. R. Pulp capping with adhesive resin-based composite vs. calcium hydroxide: a review. Dental Traumatology2000; 16, $6,240-250$.

24. Hilton T. J. Keys to clinical success with pulp capping: a review of the literature. Operative Dentistry2009; vol. 34, $5: 615-625$

25. Ber B. S, Hatton J. F, and Stewart G. P. Chemical modification of proroot MTA to improve handling characteristics and decrease setting time. JOE 2007; vol. 33, 10, 1231-1234,

26. Islam I, Chng H. K, and Jin Yap A. U. Comparison of the physical and mechanical properties of MTA and Portland cement," JOE 2006; 32, 3, 193-197. 
27. Jeon JG, Rosalen PL, Falsetta ML, Koo H. Natural products in caries research: current (limited) knowledge, challenges and future perspective. Caries Res 2011;45: 243-263.

28. Joshi S, Joshi C. Management of enamel white spot lesions. J Contemp Dent 2013; 3: 133-137.

29. Deng M, Xu X, Li J, Zhou X. Bio-modification approach for novel dentine caries management by Galla chinesis extract and microbial transglutaminase. Dent Hypotheses 2012; 3: 129-132.

30. Belduz N, Yilmmaz Y, Ozbek E, Kalkan Y, Demirci T. The effect of neodymium-doped yttrium aluminum garnet laser irradiation on rabbit dental pulp tissue. Photomed Laser Surg. 2010; 28 (6): 747-750.

31. Haddad M, Lefranc G, Aftimos G. Local application of IGF1 on dental pulp mechanically exposed; in vivo study on rabbit. Bull Group Int Rech Sci Stomatol Odontol. 2003; 45(1): 12-17.

32. Sabir A, Abbu CR, Agustiono P, Sosroseno W. Hisological analysis of rat dental pulp tissue capped with propolis. J Oral Sci. 2005;47 (3): 135-138.

33. Konigswald Wv, Golenishev FN. A method for determining growth rates in continuously growing teeth. J Mammalogoy 1979; 60: 397-400.
34. Mente, J, Geletneky B, Ohle, M, Koch, M.J, Ding, P.G, Wolff, D. Dreyhaupt, J.; Martin, N.; Staehle, H.J.; Pfefferle, T. Mineral trioxide aggregate or calcium hydroxide direct pulp capping: An analysis of the clinical treatment outcome. JOE 2010, 36, 806-813.

35. Pérard, M, Le Clerc, J, Meary, F, Pérez, F, Tricot-Doleux, S, Pellen-Mussi, P. Spheroid model study comparing the biocompatibility of Biodentine and MTA. J. Mater. Sci. Mater. Med. 2013,24, 1527-1534.

36. Cheng L, Li J, Hao Y, Zhou X.. Effect of compounds of Galla chinensis on remineralization of enamel surface in vitro. Arch Oral Biol 2010;55: 435-440.

37. Huang XL, Liu MD, Li JY, Zhou XD, ten Cate JM. Chemical composition of Galla chinensis extract and the effect of its main component(s) on the prevention of enamel demineralization in vitro. Int J Oral Sci 2012; 4: 146-151.

38. Tang B, Yuan H, Cheng L, Zhou X, Huang X, Li J. Effects of gallic acid on the morphology and growth of hydroxyapatite crystals. Arch Oral Biol2015; 60: 167-173.

39. Zhang J, Huang X, Huang S. Changes in composition and enamel demineralization inhibition activities of gallic acid at different $\mathrm{pH}$ values. Acta Odontol Scand 2015;3: 1-7. 